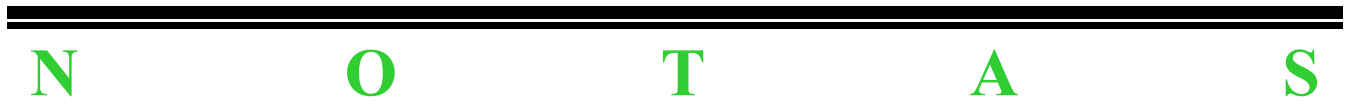




\section{ALGUNAS REFLEXIONES MÁS ACERCA DEL CONCEPTO DE TOLERANCIA. COMENTARIOS A LOS COMENTARIOS DE PABLO NAVARRO}

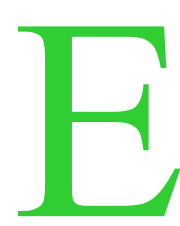

n el número 13 de Doxa (págs. 277-284) Pablo Navarro ha formulado agudas observaciones a mi propuesta de clarificación del concepto de tolerancia. En lo que sigue me referiré brevemente a ellas.

1. Navarro considera que si un enunciado de tolerancia implica un enunciado normativo que afirma que el acto tolerado está prohibido en el sistema básico $\left(S_{b}\right)$ esta implicación «es problemática» (pág. 279).

$\mathrm{Si}$ el juicio de Navarro fuera verdadero, ello significaría el derrumbe de mi construcción conceptual. Veamos, pues, más de cerca qué puede querer decir «es problemática». Por lo tanto, podría significar que el enunciado de tolerancia no implica ningún enunciado con respecto al status normativo de $X$ en el $S_{b}$ de $a$. Dicho con otras palabras: del hecho de que $a$ tolere $X$ no puede inferirse nada con respecto al status que tiene $X$ en su $S_{b}$. Me cuesta entender qué querría decir entonces tolerar: se habría negado todo carácter normativo al acto de tolerar.

Pero quedan otras dos maneras de entender «problemática»:

i) el enunciado de tolerancia implica que no existe ningún enunciado normativo con respecto a $X$ en el $S_{b}$ de $a$. En este caso, habría que concluir que toleramos actos que nos son deónticamente indiferentes en nuestro $S_{b}$. No sé qué podría significar esto desde la perspectiva del sujeto tolerante. Si alguien le preguntara por qué tolera este acto (que para el interrogado sería) deónticamente neutro, lo más probable es que reaccionara con una cierta sorpresa y dijera que ni siquiera se había dado cuenta de la existencia del acto en cuestión. Es el caso del distraído o del indiferente. Lo único que se habría logrado con la aceptación de esta posibilidad sería una confusión conceptual entre distracción, indiferencia y tolerancia. Este no parece ser un resultado deseable. 
ii) El enunciado de tolerancia implica que el status deóntico de $X$ en el $S_{b}$ de $a$ no es el de prohibido sino el de permitido o hasta ordenado. Pero, si alguien anduviera por el mundo diciendo que tolera lo que según él está permitido u ordenado, la sorpresa sería entonces la del observador: estaría, en el mejor de los casos, frente a un «redundante deóntico» que permite lo permitido y lo ordenado; en el peor, frente a un sujeto en cuyo sistema deóntico las permisiones son tan débiles que se confunden con actos de tolerancia. Sería el caso de un «permisor indeciso» con inquietantes rasgos totalitarios ya que desconocería las permisiones fuertes y hablaría, por ejemplo, de «tolerancia» de la libertad religiosa o «toleraría» que las mujeres pudieran ser equiparadas jurídicamente a los hombres.

Sin embargo, podría aducirse que he rechazado apresuradamente la primera alternativa, es decir, la que negaba el carácter normativo de los enunciados de tolerancia ya que para que pueda hablarse de tolerancia bastaría el deseo de prohibir algo que todavía no está prohibido. Esta es una interesante sugerencia y sobre ella habré de volver más adelante en 2.3 .

2. Desde luego, Navarro podría argumentar que mi respuesta no ha tomado en cuenta las razones que él mismo expone para justificar su juicio y que aun cuando hubiera que aceptar al «redundante deóntico» (lo que sobra no daña) y al «permisor indeciso» (más vale la duda que la certeza infundada) ello sería siempre mejor que incurrir en implicaciones problemáticas. Veamos pues sus razones.

Según Navarro la implicación entre el enunciado de tolerancia y el enunciado normativo de prohibición es problemática porque:

2. 1. «Puede ser que para el sujeto $b$ el acto $X$ sea obligatorio en $S_{b}$ y en $S_{j}$. Por ejemplo, una vestimenta informal puede estar prohibida en el $S_{b}$ de Mary Warnock y, sin embargo, ser obligatoria en el $S_{b}$ de su hijo» (pág. 279 ss.). A ello puede responderse con dos observaciones: i) el ejemplo no viene al caso ya que se trata de la comparación de dos $S_{b}$ y no de la relación entre un $S_{b}$ y un $S_{j}$ de una misma persona, que es a lo que Navarro parece querer referirse. Pero, además, ii) es obvio que cuando se dan casos de tolerancia entre $a$ y $b$, por lo menos sus $S_{b}$ tienen que entrar en conflicto. El que también tenga que haber conflicto entre los dos $S_{j}$ es algo que es irrelevante para el caso de la tolerancia: $a$ creerá que $X$ está prohibido en su $S_{b}$ y sólo la reflexión a nivel de su $S_{j}$ contendrá su deseo de mantener la prohibición. Por su parte, $b$ creerá que $X$ está permitido u ordenado en su $S_{b}$ y, tras reflexión a nivel de su $S_{j}$, creerá que $X$ está permitido u ordenado. Si creyera que está prohibido procuraría no realizar $X$. En el primer caso, $a$ tiene la oportunidad de ser tolerante; en el segundo, no. 
Esta primera razón de Navarro no me parece, pues, convincente. Tampoco alcanzo a comprender por qué «desde el punto de vista interno del hijo» la afirmación de Mary Warnock en el sentido de ser tolerante puede ser interpretada como «una muestra de hipocresía». Navarro promete: «volveré sobre esta cuestión en el apartado 6» (pág. 280). Dado que la promesa no es cumplida, el lector (al menos yo) queda sin saber por qué Mary Warnock ha de ser calificada de «tolerante hipócrita» o de «hipócrita» sin más. Pero, además, si se está hablando de la tolerancia de Mary Warnock, es totalmente irrelevante cuál pueda ser el «punto de vista interno del hijo». Podría hasta suceder que ni siquiera se diera cuenta que su madre es tolerante (actitud frecuente no sólo en los vástagos de los Warnocks). Debo confesar que no alcanzo a comprender cuál puede ser la contribución de esclarecimiento que proporciona el recurrir a la concepción del punto de vista interno, ya que éste está referido a la actitud de las personas con respecto a su propio sistema normativo. El hijo adopta un punto de vista interno con respecto a sus $S_{b}$ y $S_{j}$, pero no puede adoptarlo, por definición de «punto de vista interno» (si se acepta la concepción hartiana) con respecto a $\operatorname{los} S_{b}$ y $S_{j}$ de su madre.

Veamos la segunda razón:

2.2. Según Navarro, la «cronología» de la tolerancia es la siguiente: «en el momento $t_{o}$ está prohibido $X$ en el $S_{b}$ de $a$, en el momento $t_{1} a$ tolera $X$ y esto resulta en la derogación de $X$ en $S_{b}$ a partir de $\left.t_{l}\right\rangle$ (pág. 280). El argumento de Navarro se centra en la relación entre derogación y permisión fuerte. Si todos los casos de tolerancia se redujesen a casos similares a los de la Patente de tolerancia de José II, Navarro tendría razón. Pero tal no es el caso. Ello es lo que vuelve también más escurridizo el concepto de tolerancia. Por eso, en mi texto, no menciono sólo los casos en los que se deroga sino también aquéllos en los que se «levanta» reiteradamente una prohibición. Que ello pueda dar lugar a un derecho es algo que también he considerado en mi texto cuando recuerdo que en la genealogía de las permisiones fuertes suelen figurar actos de tolerancia. Pero, al igual que en la genealogía de las personas, conviene distinguir los abuelos (actos de tolerancia) de los nietos (permisiones fuertes, autorizaciones, derechos subjetivos o como quiera llamárselos). Si se identifica siempre tolerar con permisión fuerte y definitiva, pierde interés el discurso sobre la tolerancia. Una vez que $X$ está permitido en el $S_{b}$ de $a$, deja de ser objeto de un acto de tolerancia por parte de $a$. Por ello, los problemas de la tolerancia se presentan sólo en la medida en que $X$ siga estando prohibido en el $S_{b}$ de $a$. Precisamente porque ello es así no vale la segunda razón de Navarro. Veamos la tercera: 
2.3. La tercera razón está constituida por diferentes pasos que derivan de la negación del enunciado « $X$ está prohibido en el $S_{b}$ de $a »$ :

i) Según Navarro bastaría que $a$ tenga el deseo de prohibir $X$ (pág. 281). ¿Qué querría decir esto? Sólo hay dos posibilidades: i) que $X$ esté ya prohibido en el $S_{b}$ de $a$; ii) que no lo esté. Navarro rechaza i) y acepta ii). Vista más de cerca, esta posibilidad significa que $a$ tiene el deseo de prohibir algo hasta ahora permitido; pero se trata de un deseo que, en última instancia, no se manifiesta en ningún acto concreto ya que $a$ deja que las cosas sigan como antes. Si $a$ no es incoherente, es decir, no realiza (pudiéndolo, pues tiene competencia para ello) las cosas que desea (¿qué querría decir que alguien tiene deseo de realizar algo que no realiza pudiéndolo?) ello equivale a decir que el deseo de $a$ no era muy fuerte y fue desplazado por otro. Lo más que podría afirmarse en este caso es que $a$ tenía dudas acerca de la necesidad o conveniencia de introducir una prohibición. Dejando de lado los problemas de investigación psicológica que se necesitarían para verificar el enunciado « $a$ tiene dudas acerca de si $X$ debe ser prohibido en su $S_{b}$ », la explicación más plausible de la actitud de $a$ es que $a$ confirmó el status deóntico de $X$ en su $S_{b}$ tras haber consultado su $S_{j}$. Su $S_{b}$ se mantiene como antes: él era y sigue siendo el origen de sus deseos. Desde luego, éste no sería un caso de tolerancia. Quedaría, pues, eliminada la posibilidad de negar carácter normativo a los actos de tolerancia, posibilidad que había dejado abierta en 1 .

Navarro podría argumentar ahora que la palabra «deseo» significa lo mismo que «tendencia» en mi definición de la tolerancia y que si estoy dispuesto a aceptar esta plausible sinonimia no ve por qué haya de tener tantos problemas con los deseos de $a$. De acuerdo, sólo que no hay que olvidar que la única forma de verificar una tendencia es recurrir a «enunciados reduccionales» (Carnap) o a «enunciados sintomáticos» (Hempel) que describen estados de cosas (en el caso de la tolerancia, la modificación del status normativo de $X$ en el $S_{b}$ de $a$ ). Si así no fuera, valdrían para las tendencias lo mismo que he dicho con respecto a los deseos.

ii) Según Navarro «a los efectos de la tolerancia, no es necesario derogar (levantar, cancelar) una prohibición. [...] es suficiente que el sujeto competente se abstenga deliberadamente de dictar una norma que prohíba $X$ en $S_{b}$ » (pág. 281). Este argumento es una reformulación del anterior: ¿qué quiere decir abstenerse?, ¿qué tenía el deseo de prohibir $X$ y al final no lo hizo? El adverbio «deliberadamente» así parece indicarlo. ii) es reducible a i) y por economía no conviene reformular la respuesta dada en i).

iii) La tercera consideración de Navarro se refiere al caso en que $X$ no tiene status deóntico en el $S_{b}$ de $a$. No existe ninguna norma que ordene, prohíba o permita $X$; por ello, el sistema sería incompleto. 
Pero, el sistema incompleto es el del distraído o el del indiferente. Aceptar la propuesta de Navarro significa, una vez más, borrar las diferencias conceptuales entre el distraído, el indiferente y el tolerante. Por otra parte, hablar de «lagunas» en el sistema normativo de un indiferente es algo que no tiene sentido para el indiferente y hablar de lagunas en el sistema normativo del tolerante es un sinsentido. Desde el momento en que $a$ tiene el «deseo de prohibir» (condición suficiente según Navarro) ya no existiría más laguna. Cualquier cosa que haga $X$ cerrará el sistema por la simple razón de que $a$ ha dejado de ser indiferente o distraído con respecto a $X$.

iv) Al referirse a la «cronología de la tolerancia», Navarro había sostenido que «la derogación de una prohibición es una norma permisiva o permisión expresa» (pág. 280). Dicho con otras palabras y tomando el caso de José II, con la Patente de tolerancia, sus súbditos adquirieron el derecho a practicar libremente su culto, derecho que fue transmitido a sus descendientes e incluido en el «coto vedado» de los derechos fundamentales, al menos de los ciudadanos austríacos (que lo está también en los «cotos vedados» de las democracias occidentales es un hecho que nadie pone en duda). Sin embargo, a esta altura de la discusión, Navarro sostiene que mi afirmación de que aquí no se trata de un caso de tolerancia es plausible sólo porque no se hace referencia precisa a ningún sujeto tolerante. Aquí parece querer subrayar el aspecto de la competencia del tolerante. Como ésta era una condición necesaria de mi propuesta de definición del tolerante, no tengo nada que objetar. Sólo cabe observar que si se sigue el razonamiento de Navarro, tal vez hubiera sido más interesante subrayar una vez más la por él sostenida vinculación entre derogación de una prohibición y permisión fuerte.

v) Las conclusiones de Navarro difieren de las mías en el sentido de que admite como acto de tolerancia la abstención de prohibición de una conducta permitida (pág. 282), es decir, el caso en el que una conducta que hasta ahora estaba permitida en $S_{b}$ corre el riesgo de convertirse en prohibida. El tolerante de Navarro sería alguien que tendería a modificar su $S_{b}$ aumentando prohibiciones. Pero, si no lo hace es porque considera que el $S_{b}$ es correcto y no tiene ninguna razón para modificarlo; sería el caso del tolerante que tolera lo permitido (redundancia deóntica: permite lo permitido); si introdujera una nueva prohibición reduciendo el ámbito de lo permitido, cuesta admitir que ello sea una manifestación de tolerancia. Dicho con otras palabras: la tendencia a prohibir lo permitido es un dato que sugiere más intolerancia que tolerancia.

3. Estoy plenamente de acuerdo con Navarro por lo que respecta al problema de la intolerancia como negación interna de la tolerancia. 
Es justamente lo que afirmo en la frase citada por Navarro en la pág. 283. Por ello no entiendo el «sin embargo» que precede a la cita. El problema que me interesaba considerar era cómo puede explicarse que, en algunos casos, para ser tolerantes hay que ser también simultáneamente intolerantes (caso de la reunión del Lago de Wann). Ello no me parece tan obvio. En efecto, si se admite que ayunar es la negación interna de comer, suena bastante raro decir que para ayunar hay que comer (al mismo tiempo). O sea que aquí había un cierto problema o, al menos, algo que podía dejarnos perplejos. Es obvio que esta perplejidad no puede ser definitiva. Por eso pensé que la idea del «cerco de intolerancias» era plausible. El «cerco» es lo que hace que el «coto» sea «vedado»; está constituido por aquello que no puede ser tolerado, es decir, es intolerable. Pero es claro que los actos intolerables no pueden ser los mismos que los tolerables. En este sentido, la referencia sin más a la intolerancia puede parecer en un primer momento paradójica. Pero creo que esta impresión es instructiva, pues pone de manifiesto que la tolerancia no es algo que pende en el aire sino que tiene que estar enmarcada por intolerancias. En todo caso, si mi propuesta es aceptable o no es algo que no se resuelve haciendo referencia a la negación externa de la tolerancia.

4. Coincido con Navarro en el sentido de que para la resolución de un conflicto entre diferentes $S_{j}$ hay que contar con criterios objetivos. En el punto 15 de mi artículo he tratado de explicitar qué entiendo por «buenas razones» para determinar si una acción es tolerable o intolerable. Si se acepta mi propuesta, no hay la menor duda de que el «principio de no dictadura» es inadecuado si se lo aplica a la reunión del Lago de Wann ya que conduce no a una mera tolerancia boba sino criminal.

5. La discusión con interlocutores agudos es siempre refrescante e instructiva. Las observaciones de Pablo (Navarro) me han servido para repensar mis argumentos. El hecho de que los suyos no me hayan convencido no prueba nada más que sigo creyendo en la plausibilidad de mi propuesta conceptual. Pero pretensión de plausibilidad no es pretensión de verdad. En esto coincido también con Navarro. Y sé también que ambos coincidimos en la necesidad de la discusión franca no sólo como señal de que se toman en serio los argumentos de la otra parte (lo que equivale a tomarla en serio también como sujeto moral) aun cuando no se esté de acuerdo, es decir, cuando existe la tendencia a no considerarlos (por ello la discusión honesta es también un ejercicio de tolerancia) sino como la vía más fecunda para lograr una mayor claridad conceptual en un campo sembrado de imprecisiones, retórica y malas razones como es el de la filosofía moral. 